\title{
EFFECT OF THE pH ON THE ABSORPTION SPECTRUM OF THE ISOLATED D1-D2-CYTOCHROME b559 COMPLEX OF PHOTOSYSTEM II
}

Inmaculada Yruela ${ }^{1}$, Raquel Tomás ${ }^{1}$, Miguel Alfonso ${ }^{1}$ and Rafael Picorel ${ }^{1,{ }^{*}}$

${ }^{1}$ Estación Experimental de Aula Dei, Consejo Superior de Investigaciones Científicas (C.S.I.C.), Apdo. 202, E-50080-Zaragoza, Spain.

*To whom correspondence should be addressed. FAX: 34-976-575620.

e-mail: picorel@eead.csic.es.

Keywords: absorption, spectroscopy, photosystem II, pH, reaction center.

ABBREVIATIONS: Chl, chlorophyll; Cyt, cytochrome; D1 and D2, core polypeptides of the photosystem II reaction center; MES, 2-(N-morpholino)ethane-sulphonic acid; P680, primary chlorophyll donor of the photosystem II reaction center; Pheo, pheophytin; RC, reaction center; Tris, tris(hydroxymethyl)aminomethane. 


\section{ABSTRACT}

The effect of $\mathrm{pH}$ on the $\mathrm{Q}_{y}$ absorption band was studied in the isolated D1-D2-cytochrome $b 559$ complex. The pH-treatments were done on an ionexchange chromatographic column. The absorption spectra at $77 \mathrm{~K}$ of the complex treated with acidic $\mathrm{pH}$ showed irreversible loss of absorbance at both the blue and the red sides of the $\mathrm{Q}_{\mathrm{y}}$ absorption band with minima at 664.5 and $683.5 \mathrm{~nm}$, respectively. These absorption changes were not accompanied by modifications on the $\mathrm{Q}_{\mathrm{x}}$ absorption region characteristic of pheophytin pigments. Furthermore, the pigment composition of the D1-D2-cytochrome $b 559$ complex remained unchanged after this treatment. The effects of basic $\mathrm{pH}$ effects were similar to that of the acidic $\mathrm{pH}$, but somewhat more pronounced. These results suggest that chlorophyll pigments absorbing at 664.5 and $683.5 \mathrm{~nm}$ are located on or close to the surface of the complex. Freezing/thawing cycle treatment firstly affected the band absorbing at $683.6 \mathrm{~nm}$ indicating that it corresponds to the chlorophyll most exposed to the medium in the D1-D2-cytochrome b559 complex. At lower $\mathrm{pH}$ than 5 a small reversible change at $672.5 \mathrm{~nm}$ was measured that correlated with a reversible change at $542 \mathrm{~nm}$, indicating that inactive pheophytin a would absorb at this wavelength. 


\section{INTRODUCTION}

Photosystem II (PSII) is a multisubunit complex inserted into the thylakoid membranes of photosynthetic organisms (higher plants, algae and cyanobacteria). It uses light-energy to catalyze a series of electron transfer reactions which result in the splitting of water into molecular oxygen, protons and electrons (for reviews see 1-3). The primary photochemical processes that drive the water-splitting reaction occur in the reaction center (RC) of PSII which in its isolated form consists of the D1 and D2 polypeptides, the $\alpha$ and $\beta$ subunits of the cytochrome (Cyt) b559 and the psbl gene product $(4,5)$. This complex, known as the D1-D2-Cyt b559 complex, binds in addition to P680 and pheophytin (Pheo) a number of accessory chlorophylls (Chl). At present, the current accepted chlorine content is 6 Chls and 2 Pheos per RC complex, though preparations containing 4 and $5 \mathrm{Chl}$ per 2 Pheo have also been reported $(3,6,7)$. The spectroscopic and functional studies on the isolated D1-D2-Cyt b559 complex are complicated by the fact that all the chlorine pigments contribute to the $\mathrm{Q}_{\mathrm{y}}$ absorption and fluorescence bands of the complex in the range 670-690 nm [for reviews see Renger (1992) and Barber (1994)]. Although considerable research based on spectroscopic measurements has been done to investigate the assignment of the single pigments, there is still no consensus on the exact positions in the absorption spectrum, particularly with respect to the accessory Chls and Pheo.

An interesting feature of the native biological photosynthetic systems is the redshifting of their pigment absorption bands compared to the pigments in solution. This phenomenon is remarkable in bacterial photosynthetic complexes 
and has been the aim of numerous studies (10-12). Two main theories have been proposed to explain it. One of them attributes a good part of the spectroscopic properties of bacteriochlorophyll (BChl) in vivo to strong interactions of the BChl with the holder apoprotein (13-15). The other theory relates the redshifting to strong excitonic interactions among closely spaced BChl molecules (16-19). However, the most likely explanation seems to be a combination of both $(15,20)$.

To further investigate the organisation of pigments in their surrounding proteins different methods such as freezing (21), proteolysis (22), treatment with detergents and sodium chloride (12) and chemical modifications with sodium borohydride (23) or ferricyanide (24) were used in studies performed on the bacterial reaction center and antenna complexes. In the PSII RC the excitonic interactions between pigments are much less stronger than that in the case of bacterial RCs, however they have also been aim of interest (25-27). Recently, some of the treatments mentioned above have been applied to investigate the electronic absorption properties of the PSII RC $(28,29)$. These studies have reported on the position of the inactive Pheo (29) in the absorption spectrum of the D1-D2-Cyt b559 complex. However, there is still no consensus on the assignment of most of the accessory and "antenna" Chls in the PSII RC. The former pigments correspond to Chls homologous to the accessory BChls in RC from purple bacteria and the second ones to the "extra" Chls present in the PSII $\mathrm{RC}$ from higher plants compared to that of bacteria (30). In the present work we report the absorption spectral changes induced at different $\mathrm{pH}$ and after freezing/thawing cycles on the D1-D2-Cyt b559 complex isolated from higher plants. 


\section{MATERIALS AND METHODS}

Preparation of the D1-D2-Cyt b559 complex.- The D1-D2-Cyt b559 complex was isolated from highly purified PSIl membranes (31) according to the method of Nanba and Satoh (4) with some modifications mainly concerning to the detergent concentration. PSII membranes at $1 \mathrm{mg} / \mathrm{mL} \mathrm{Chl}$ were solubilized with 4\% (w/v) Triton X-100 for $2 \mathrm{~h}$, centrifuged at 100,000 x $\mathrm{g}$ for $1 \mathrm{~h}$ at $4^{\circ} \mathrm{C}$ and the resultant supernatant purified by ion-exchange chromatography (DEAE-Toyopearl TSK $650 \mathrm{~S}$ column) using 1\% (w/v) Triton X-100 in the column washing buffer steps (32). The detergent Triton $\mathrm{X}-100$ was subsequently replaced by $0.1 \%(\mathrm{w} / \mathrm{v}) n$-dodecyl- $\beta-D$-maltoside before a 60-350 mM NaCl linear gradient was applied. The $\mathrm{Q}_{y}$ absorption band maximum of the complex was at $675.5-676 \mathrm{~nm}$ at $4{ }^{\circ} \mathrm{C}$ indicative of the good quality of the preparation. The stoichiometry of the complex was six Chl $\mathrm{a}$ and one $\beta$-carotene per two Pheo a determined according to Eijckelhoff and Dekker (6).

Treatment with solutions at different $\mathrm{pH}$ (for details see Figure Legends) were done following two different procedures: a) by adding aliquots of $1 \mathrm{~N} \mathrm{NaOH}$ and $1 \mathrm{~N} \mathrm{HCl}$ to the samples and b) by washing the D1-D2-Cyt $b 559$ with 50 mM MES-NaOH (pH 5.5, 5.0 and 4.0) or $50 \mathrm{mM}$ Tris- $\mathrm{HCl}(\mathrm{pH} 7.5,8.1,10.0), 30 \mathrm{mM} \mathrm{NaCl}$ and $0.1 \%(w / v) n$-dodecyl- $\beta-D-$ maltoside through the ion-exchange column. The isolated preparation was eluted with $200 \mathrm{mM} \mathrm{NaCl}$ after the corresponding $\mathrm{pH}$ value was reached. In some cases, the column was again washed with $50 \mathrm{mM}$ MES-NaOH $(\mathrm{pH}$ 6.5), $30 \mathrm{mM} \mathrm{NaCl}$ and $0.1 \%(\mathrm{w} / \mathrm{v}) n$-dodecyl- $\beta-D$-maltoside to return to the 
original conditions before elution. All the steps during the preparation procedure were done in dim green light in a cooled chamber at $4^{\circ} \mathrm{C}$.

Spectroscopy.-. Absorption spectra at $4{ }^{\circ} \mathrm{C}$ were recorded with a Beckman DU 640 spectrophotometer with the temperature controlled with a Pharmacia circulating water bath. The spectra at $77 \mathrm{~K}$ were measured in the same spectrophotometer using a variable liquid nitrogen cryostat DN1704 (Oxford Instruments). For measurements at $77 \mathrm{~K}$, samples were diluted three times in glycerol. 


\section{RESULTS}

The influence of the $\mathrm{pH}$ on the $\mathrm{Q}_{\mathrm{y}}$ absorption band of the D1-D2-Cyt $b 559$ complex was investigated at room temperature and $77 \mathrm{~K}$. Treatments were done by adding aliquots of $0.1 \mathrm{~N} \mathrm{HCl}$ or $0.1 \mathrm{~N} \mathrm{NaOH}$ directly to the sample suspensions and by washing steps with buffer solutions at the corresponding $\mathrm{pH}$ through an ion-exchange chromatographic column (for details see Materials and Methods and Figure Legends). Both treatments provided similar changes in the $\mathrm{Q}_{\mathrm{y}}$ absorption maxima at $4{ }^{\circ} \mathrm{C}$ (data not shown). However, the corresponding spectra at $77 \mathrm{~K}$ showed stronger modifications in the $Q_{y}$ band in the samples treated in solution compared to those treated through the ion-exchange chromatographic column at both acidic and basic $\mathrm{pH}$ ranges. Because the $\mathrm{pH}$ conditions in solution were more difficult to control, we show in the present work the results of the experiments performed using the chromatographic column to exchange the $\mathrm{pH}$.

Figure 1 shows the influence of $\mathrm{pH} 5.5$ and 4.0 on the $\mathrm{Q}_{\mathrm{y}}$ absorption band of the D1-D2-Cyt b559 complex at 77K. Both the blue and the red sides of the band narrowed after treatment at acidic $\mathrm{pH}$ compared to those of the control spectrum at $\mathrm{pH}$ 6.5. The maximum at $678.5 \mathrm{~nm}$ shifted to the blue, the shift being $0.5 \mathrm{~nm}$ at $\mathrm{pH}$ 4.0. In contrast, the maximum at $671.1 \mathrm{~nm}$ remained unchanged in all the experimental conditions used. The reported changes on the $\mathrm{Q}_{y}$ absorption band of the D1-D2-Cyt b559 were not reversible. On the other hand, the pigment composition of the D1-D2-Cyt b559 complex did not change after the $\mathrm{pH}$ treatment, indicating that the modifications in the absorption spectra are not due to a selective loss of pigments but to changes in its electronic absorption properties. Some partially reversible changes were observed at the $\mathrm{Q}_{\mathrm{y}}$ band red-side. The blue-shift at $678.5 \mathrm{~nm}$ which was accompanied by an increment of the absorbance 
at around this wavelength, was partially reverted when the D1-D2-Cyt b559 complex preparation at $\mathrm{pH} 4.0$ was subsequently washed with solution at $\mathrm{pH} 6.5$ to get the initial experimental conditions (Fig. 1b).

The $\mathrm{Q}_{\mathrm{x}}$ absorption band at around $542 \mathrm{~nm}$ assigned to Pheo was also examined. At pH 5.5 no significant modifications were observed in this spectral region, however stronger acidic conditions such as $\mathrm{pH} 4.0$ reduced the intensity of the Pheo band around 40\% (Fig. 1b, inset). This phenomenon was reversible and the shape of $\mathrm{Q}_{x}$ absorption band at $542 \mathrm{~nm}$ in the D1-D2-Cyt b559 complex treated with $\mathrm{pH} 4.0$ and subsequently with $\mathrm{pH} 6.5$ was comparable to that of the control. The loss of absorbance at $542 \mathrm{~nm}$ was also accompanied by the appearance of a new band near to $554 \mathrm{~nm}$ and an increment of the absorbance at around $525 \mathrm{~nm}$ (Fig. 1b, inset). Changes in the $\mathrm{pH}$ conditions can modify the redox potential of the medium and consequently contribution of reduced Cyt b559 could be detected. Considering that at 77K the maximum of Cyt b559 shifts to $556 \mathrm{~nm}$ (33) the new band in the $550-560 \mathrm{~nm}$ spectral region could be assigned to a partial reduction of Cyt $b 559$. Figure $1 c$ shows in more detail the changes induced by the treatments at acidic $\mathrm{pH}$. The difference absorption spectra between those of the acid-pH-treated and control showed minima at 683.5 and $664.5 \mathrm{~nm}$, being the loss of absorbance of $14.4-15.3 \%$ and $3.5-4.5 \%$, respectively. In addition a minor minimum at around 672-674 $\mathrm{nm}$ was observed in the difference absorption spectrum between those of the treated at $\mathrm{pH} 4.0$ and non-treated D1-D2-Cyt $b 559$ complex samples (Fig. 1c). This minimum disappeared when the $\mathrm{pH}$ of the sample reverted to the control conditions (Fig. 1c). The reversible change at around 672$674 \mathrm{~nm}$ can be correlated to those observed in the $\mathrm{Q}_{x}$ absorption band region at $\mathrm{pH}$ 4.0. Similar changes were observed by Shuvalov et al. (33) during reduction of 
an extra low potential Cyt $b 559$. These authors observed a bleaching at $672 \mathrm{~nm}$ at $293 \mathrm{~K}$ assignable to reduced Pheo. The inset of Fig. 1c shows the difference absorption spectrum between the $\mathrm{pH}$ 4.0-treated sample after washed with buffer solution at $\mathrm{pH} 6.5$ and that before treatment. This difference spectra indicated that the reversible change measured in the $\mathrm{Q}_{y}$ band corresponded to a maximum at $672.5 \mathrm{~nm}$. In addition, a small reversible change was also observed at $681.7 \mathrm{~nm}$.

The effect of the basic $\mathrm{pH}$ on the absorption spectrum of the D1-D2-Cyt b559 complex is shown in Fig. 2. In general the modifications induced by the basic $\mathrm{pH}$ were stronger than those of acidic $\mathrm{pH}$. At $\mathrm{pH} 8.5$ (Fig. 2a) the $\mathrm{Q}_{\mathrm{y}}$ band slightly narrowed compared to that of the control and the decrease of the intensity of the maximum at $678.5 \mathrm{~nm}$ was accompanied by an increment of that at $671.5 \mathrm{~nm}$. The loss of absorbance at both the blue and the red sides of the $\mathrm{Q}_{\mathrm{y}}$ absorption band were no reversible. However, a reversible change in the center of this band was observed (Fig 2a). The Pheo band at $542 \mathrm{~nm}$ was not affected in these conditions. At higher $\mathrm{pH}$ values the changes were stronger as shown in the Figure $2 \mathrm{~b}$. At $\mathrm{pH}$ 10.0 the $\mathrm{Q}_{\mathrm{y}}$ absorption band shifted significantly to shorter wavelengths, the maximum at $678.5 \mathrm{~nm}$ disappeared being the new maximum of the $\mathrm{Q}_{\mathrm{y}}$ band at $670.6 \mathrm{~nm}$. The presence of a shoulder at $679-680 \mathrm{~nm}$ is indicative that not all the species that absorb at around these wavelengths are affected by the treatment. The absorption changes were partially reversible as shown in the spectrum measured after washing the sample with the control buffer at $\mathrm{pH} 6.5$ (Fig. 2b). Part of the absorbance at the red side of the $\mathrm{Q}_{\mathrm{y}}$ absorption band at around $680 \mathrm{~nm}$ was recovered, being the new maxima at $678.0 \mathrm{~nm}$. Two species have been proposed to contribute to the band at $680 \mathrm{~nm}, \mathrm{P} 680$ and active Pheo $(2,3,8)$. Since no changes were observed at $542 \mathrm{~nm}$, the reversible change at $679-680 \mathrm{~nm}$ could be 
assigned to P680. It has previously been reported that P680 is susceptible to suffer reversible induced changes by biochemical treatments such as detergent exchange (28). Reversible modifications in the $\mathrm{Q}_{\mathrm{x}}$ band region of Pheo were also induced as occurred at pH 4.0 (Fig. 1b, inset). A new band at $553 \mathrm{~nm}$ was observed (Fig. 2b, inset) which could be assigned to the reduced Cyt b559 $(33,34)$. This band disappeared again when the original experimental conditions were restored. The difference absorption spectra between those of the basic $\mathrm{pH}$ treated and control samples are shown in Fig. 2c. The changes caused by the basic $\mathrm{pH}$ treatment were more pronounced than those at acidic $\mathrm{pH}$. The treatment at $\mathrm{pH} 8.5$ (Fig. 2c) caused a loss of absorbance with minima at 683.7 and 663.8 $\mathrm{nm}$ of $11 \%$ and $7.5 \%$, respectively. These values are comparable to that calculated for the treatment at $\mathrm{pH} 4.0$, although the effect on the blue side of the spectrum seem to be slightly higher. At pH 10.0 the minima were at 681.6 and $665.1 \mathrm{~nm}$ and the associated loss of 16.9 and $4.2 \%$, respectively. Part of the loss of absorbance at $\mathrm{Q}_{\mathrm{y}}$ absorption band at basic $\mathrm{pH}$ was reversible (Fig. 2c, inset). The difference spectra between the $\mathrm{pH} 10.0$ treated samples after washing with buffer solution at $\mathrm{pH} 6.5$ and that at $\mathrm{pH} 10.0$ showed maxima at $680.5 \mathrm{~nm}$. The calculated maxima corresponded to reversible changes induced by basic $\mathrm{pH}$. As occurred at acidic pH such modifications could be assigned to P680.

The second derivatives of the absorption spectra measured after the different $\mathrm{pH}$-treatments is shown in Fig. 3. The acidic pH (Fig. 3a) modified more selectively the $680 \mathrm{~nm}$ spectral region and particularly the red side of the band absorbing at this wavelength. The shoulder at $683 \mathrm{~nm}$ was the first to disappear after the subsequent $\mathrm{pH}$-treatments. After that, the minimum at $680.7 \mathrm{~nm}$ shifted to $679.8 \mathrm{~nm}$ at $\mathrm{pH} 5.5$ and $679.3 \mathrm{~nm}$ at $\mathrm{pH}$ 4.0. Although in general the modifications 
at basic $\mathrm{pH}$ were more pronounced, the second derivative spectrum showed that the results at $\mathrm{pH} 8.1$ (Fig. 3b) are comparable to those at $\mathrm{pH} 5.5$ (Fig. 3a). It seems again that the band absorbing at $683 \mathrm{~nm}$ is firstly affected.

Freezing methods have also been used to investigate the properties of photosynthetic pigment-protein complexes (21). It is known that the stability and integrity of the D1-D2-Cyt b559 complex is affected by freezing and storage procedures. In order to study in more detail which is the effect of freezing in this new preparation we measured the absorption spectra of the D1-D2-Cyt b559 complex at 277 and $77 \mathrm{~K}$ complex after different freezing/thawing cycles at $193 \mathrm{~K}$ and $77 \mathrm{~K}$. Figure 4 shows that freezing in liquid nitrogen $(77 \mathrm{~K})$ conserved more intact the D1-D2-Cyt $b 559$ complex preparations than at 193K. The Qy absorption band maximum measured at $277 \mathrm{~K}$ remained quite stable after eight freezing/thawing cycles at $77 \mathrm{~K}$ in contrast to what occurred at $193 \mathrm{~K}$. The comparison of the absorption spectra measured at $77 \mathrm{~K}$ after the different treatments at $193 \mathrm{~K}$ showed that the Chl pigment(s) absorbing at $682-684 \mathrm{~nm}$ was(were) the most affected and no significant changes were caused on the Pheo molecules (Fig. 5). The loss of absorbance after four and eight freezing/thawing cycles at 683.6 and $682.7 \mathrm{~nm}$ was $10 \%$ and $21 \%$, respectively. The values are in the same order of magnitude than those calculated after acidic $\mathrm{pH}$ treatment. 


\section{DISCUSSION}

The experiments based on the modifications of the $\mathrm{pH}$ conditions in the isolated D1-D2-Cyt b559 complex samples reported in this work revealed that the absorption bands with maxima at 683.5 and $664.5 \mathrm{~nm}$ that contribute to the $\mathrm{Q}_{\mathrm{y}}$ absorption band are selectively first modified by both acidic and basic $\mathrm{pH}$ treatments. These changes were observed even with slight $\mathrm{pH}$ changes from 6.5 to 5.5 or 8.5 . The maxima affected by the milder treatments were assigned to Chls since no changes at the Pheo $\mathrm{Q}_{\mathrm{x}}$ band region were observed in the same conditions. The fact that the pigment composition of the D1-D2-Cyt b559 complex was not modified during the $\mathrm{pH}$ treatment suggest that the observed spectral changes are not due to the loss of specific pigments. Thus, the spectral changes must be explained by some modifications of the protein matrix.

The stability of proteins is highly dependent on $\mathrm{pH}$ since hydrogen bonds, which are essential for the secondary structure of most proteins, are very sensitive to $\mathrm{pH}$ changes of the environment and associated protonations and deprotonations. Changes in the PSII RC due to $\mathrm{pH}$ have also been investigated in the past $(35,36)$. It is also known that hydrogen bonds are formed between some amino acid residues and Chls in the D1-D2-Cyt b559 complex which have a structural role in binding and orienting the pigment molecules (37). Particularly, Chl absorbing at $683.5 \mathrm{~nm}$ was the most affected by slight changes in the $\mathrm{pH}$ conditions. Furthermore, the percentage of $\sim 15 \%$ loss of absorbance at this wavelength was comparable to the calculated contribution $(\sim 14 \%)$ of a gaussian with maximum at $683.2 \mathrm{~nm}$ to the absorption spectra of the isolated D1-D2-Cyt b559 complex reported by Konermann and Holzwarth (30). This finding indicated that the chromophore absorbing at this wavelength was quantitatively modified. 
The nature of this chromophore absorbing at the red-edge of the absorption spectrum has been discussed in recent years $(25-27,30,38,39)$. The presence of a shoulder at $684 \mathrm{~nm}$ is a typical spectral feature of most PSII RC preparations obtained in different laboratories. However, those preparations clearly differed from each others in the size of the contribution of this band to the total spectra (30). Based on these findings, some authors postulated that the shoulder at 684 $\mathrm{nm}$ could be caused by additional Chls not actually belonging to the PSII RC (30). However, samples with $6 \mathrm{Chl} / 2$ Pheo and clearly free of contamination $(30,32)$ also presented a pronounced shoulder at $684 \mathrm{~nm}$, indicating that this band is not caused by a red-absorbing $\mathrm{Chl}$ contaminant. On the other hand, it has recently shown that the absorption spectrum of PSII RC particles containing $5 \mathrm{Chl} / \mathrm{RC}$ reveals that the shoulder near $684 \mathrm{~nm}$ is more pronounced than in any other PSII $\mathrm{RC}$ preparation.

Excitonic coupling due to pigment-pigment interactions have also been described in the D1-D2-Cyt b559 complex. The dimeric nature of P680 has been extensively discussed. Based on hole-burning measurements at low temperatures, the Qy band of P680 absorption spectrum consists of two excitonic bands one peaking at around $667 \mathrm{~nm}$ and the other at $681 \mathrm{~nm}(26)$. These results are in good agreement with circular dichroism $(35,40)$ and triplet-minus-singlet absorption difference spectra (27). The fact that the Chls absorbing at 683.5 and $664.5 \mathrm{~nm}$ are selectively affected by $\mathrm{pH}$ treatments could suggest that both pigments are excitonically coupled. Kwa et al. (27) reported that the triplet-minus-singlet absorption spectrum ascribed to P680 can be interpreted in terms of a dimer with two distinguishable distributions around 681 and $684 \mathrm{~nm}$ which contribute to the low-energy exciton band and the upper dimer component peaking at $667 \mathrm{~nm}$. 
More recently, spectroscopic data on 5ChI PSII RC preparation indicated that the low energy shoulder at $684 \mathrm{~nm}$ originates, at least in part, from the primary electron donor P680 (41). This model is not consistent with our freezing/thawing cycle treatments, except if we consider that only a minor part of the absorbance at $684 \mathrm{~nm}$ corresponds to P680 and other species absorb at this wavelength. Our treatments caused selective loss of absorbance at $683 \mathrm{~nm}$ that was not accompained by significant effect on the blue side of the Qy absorption band (Fig. 5b). The $684 \mathrm{~nm}$ absorption band has been also found to be easily disrupted by the ionic detergent Triton X-100 (26).

Spectral gaussian deconvolution analyses and site-selection fluorescence spectroscopic measurements have identified the lowest energy pigment in the PSII $\mathrm{RC}$ as an accessory $\mathrm{Chl}$ which is not related to P680 and is analogous to one of the accessory BChl in the bacterial RC $(30,38)$. The fact that the Chl absorbing at $683 \mathrm{~nm}$ was the pigment first affected by pH-treatments (Fig. 1c, 2c, 3) seems to indicate that it should be in a protein region highly exposed to the medium. Furthermore, these considerations are also supported by our freezing/thawing cycle experiments. Indeed, the $\mathrm{Chl}$ absorbing at $683 \mathrm{~nm}$ was the most susceptible to damage by the freezing/thawing cycle procedure at $193 \mathrm{~K}$, suggesting that it should be more exposed to the surface of the complex. Distances of 9.9 and 10.4 $\AA$ A between D1-accessory $\mathrm{Chl}$ and D1-Chl(P680) and active D1-Pheo, respectively have been calculated (37). Although there is no data concerning to the analogous distances from D2-accessory $\mathrm{Chl}$ to $\mathrm{D} 2-\mathrm{Chl}(\mathrm{P} 680)$ and inactive D2-Pheo the values should be similar. Thus, these accessory Chls would correspond to the inner chromophores which together with the P680 and the Pheo constitute the "core pigment" of the PSII RC. 
In the present work we have showed that Chl absorbing in the blue side of the absorption spectra is also affected by the $\mathrm{pH}$ but the freezing/thawing cycle treatments did not cause significant changes in this spectral region. These findings suggest a location of the pigment absorbing at $667-670 \mathrm{~nm}$ spectral region exposed to the medium but more protected by the matrix than that absorbing at $684 \mathrm{~nm}$. The highest energy pigment in the PSII RC has been assigned by others to one of the"extra" Chls called "antenna" Chls in the D1-D2-Cyt b559 complex (30). These results are in agreement with spectroscopic data on the $5 \mathrm{Chl}-\mathrm{RC}$ preparation $(7,41)$. They indicated that the $\mathrm{Chl}$ removed belongs to a pool of $\mathrm{Chl}$ absorbing at $670 \mathrm{~nm}$ likely to be peripherally bound.

The treatment with stronger $\mathrm{pH}$ conditions as $\mathrm{pH} 4.0$ caused additional reversible modifications in the $\mathrm{Q}_{\mathrm{x}}$ Pheo spectral region which were accompanied by reversible changes in $\mathrm{Q}_{\mathrm{y}}$ absorption band at around $672-674 \mathrm{~nm}$. Since, there is a general consensus that the active Pheo absorbs close to $680 \mathrm{~nm}$, this maximum should correspond to the inactive Pheo. At present, there is no consensus on the exact position of the inactive Pheo and it has been proposed that it absorbs at 671 (42) and $680 \mathrm{~nm}$ (29). Our results support the conclusion that the inactive Pheo most probably has a maximum in the $672-674 \mathrm{~nm}$ spectral region. 


\section{ACKNOWLEDGEMENTS}

This work was supported by the Dirección General de Investigación Científica y Técnica (Grant PB95-0219). 


\section{REFERENCES}

1. K. Satoh. Isolation and properties of the Photosystem II reaction center. In Deisenhofer, J. and Norris, J.R. (eds). The Photosynthetic Reaction Center. Academic Press, San Diego, CA (1993) 289-318.

2. M. Seibert. Biochemical, biophysical, and structural characterization of the isolated Photosystem II reaction center complex. In Deisenhofer, J. and Norris, J.R. (eds). The Photosynthetic Reaction Center, Academic Press, San Diego, CA (1993) pp. 319-356.

3. K. Satoh. Introduction to the Photosystem II reaction center. Isolation and biochemical and biophysical characterization. In Ort, D.R. and Yocum, C.F. (eds). Oxygenic Photosynthesis: The Light Reactions, Kluwer Academic Publishers, The Netherlands (1996) 193-211.

4. O. Nanba and K. Satoh. Isolation of a photosystem II reaction center consisting of D1 and D2 polypeptides and cytochrome b559. Proc. Natl. Acad. Sci. USA 84 (1987) 109-112.

5. J. Barber, D.J. Chapman and A.Telfer. Characterization of a PSII reaction centre isolated from the chloroplasts of Pisum sativum. FEBS Lett. 220 (1987) 67-73.

6. C. Eijckelhoff and J.P. Dekker. A routine to determine the chlorophyll a, pheophytin $a$ and $\beta$-carotene contents of isolated photosystem II reaction center complexes. Photosynth. Res. 52 (1997) 69-73.

7. F. Vacha, D.M. Joseph, J.R. Durrant, A. Telfer, D.R. Klug, G. Porter and J. Barber. Photochemistry and spectroscopy of a five-chlorophyll reaction center 
of photosystem II isolated by using a Cu affinity column. Proc. Natl. Acad. Sci., USA 92 (1995) 2929-2933.

8. G. Renger. Energy transfer and trapping in photosystem II. In J. Barber (ed.). Topics in Photosynthesis, Vol 11, The Photosystems: Structure, Function and Molecular Biology, Elsevier, Amsterdam. (1992) 45-99.

9. J. Barber. Photosystem II no longer the black box of photosynthesis. Biochem. Soc. Trans. 22 (1994) 313-318.

10. H. Scheer, M. Meyer and I. Katheder. Bacterial reaction centers with planttype pheophytins. In J. Breton and A. Vermeglio (eds.). The Photosynthetic Bacterial Reaction Center II: Structure, Spectroscopy and Dynamics NATO ASI Series A: Life Sciences, Vol. 237 Plenum Press, New York. (1992) 49-57.

11. A.Ya. Shkuropatov, I.I. Proskuryakov, V.A. Shkuropatova, M.G. Zvereva, and V.A. Shuvalov. Formation of charge separated state $\mathrm{P}(+) \mathrm{Q}_{\mathrm{A}}(-)$ and triplet state ${ }^{3} \mathrm{P}$ at low temperature in Rhodobacter sphaeroides (R-26) reactions centers in which bacteriopheophytin $a$ is replaced by plant pheophytin a. FEBS Lett. 351 (1994) 249-252.

12. I. Ortiz de Zarate and R. Picorel. Spectral changes of the B800-850 antenna complex from Ectothiorhodospira sp. induced by detergent and salt treatment. Photosynth. Res. 41 (1994) 339-347.

13. C.N. Rafferty, J. Bolt, K. Sauer and R.K. Clayton. Photooxidation of antenna bacteriochlorophyll in chromatophores from carotenoidless mutant Rhodopseudomonas sphaeroides and the attendant loss of dimeric exciton interaction. Proc. Natl. Acad. Sci. USA 76 (1979) 4429-4432.

14. J. Eccles and B. Honing. Charged amino acids as spectroscopic determinants for chlorophyll in vivo. Proc. Natl. Acad. Sci. USA 80 (1983) 4959-4962. 
15. R. Picorel, A. L' Ecuyer, M. Potier, G. Gingras. Structure of the B880 holochromes isolated from three species of photosynthetic bacteria as studied by electron paramagnetic resonance and radiation inactivation method. J. Biol. Chem. 261 (1986) 3020-3024.

16. J. Gottstein and H. Scheer. Long-wavelength-absorbing forms of bacteriochlorophyll a in solutions of Triton X-100. Proc. Natl Acad. Sci. USA 80 (1983) 2231-2234.

17. A. Scherz and W.W. Parson. Oligomers of bacteriochlorophyll and bacteriopheophytin with spectroscopic properties resembling those found in photosynthetic bacteria. Biochim. Biophys. Acta 766 (1984) 653-665.

18. A. Scherz, and V. Rosenbach-Belkin. comparative study of optical absorption and circular dichroism of bacteriochlorophyll oligomers in Triton X-100, the antenna pigment B850, and the primary donor P680 of photosynthetic bacteria indicates that all are similar dimers of bacteriochlorophyll a. Proc. Natl. Acad. Sci. USA 86 (1989) 1505-1509.

19. P. Braun and A. Scherz. Polypeptides and bacteriochlorophyll organization in the light-harvesting complex B850 of Rhodobacter sphaeroides R-26.1. Biochemistry 30 (1991) 5177-5184.

20. G.J.S. Fowler, R.W. Visschers, G.G. Grief, R. van Grondelle and C.N. Hunter. Genetically modified photosynthetic antenna complexes with blueshift absorbance bands. Nature 335 (1991) 848-850.

21. K. Sauer and L.A. Austin. Bacteriochlorophyll-protein complexes from the light-harvesting antenna of photosynthetic bacteria. Biochemistry 17 (1978) 2011-2019. 
22. G.D. Webster, R.J. Cogdell and G. Lindsay. The location of the carotenoid in the B800-850 light-harvesting pigment-protein complex from Rhodopseudomonas capsulata. FEBS Lett. 111 (1980) 391-394.

23. B.W. Chadwick, G. Zhang, R.J. Cogdell, H.A. Franck. The effects of lithium dodecyl sulfate and sodium borohydride on the absorption spectrum of the B800-850 light-harvesting complex from Rhodopseudomonas sphaeroides. Biochim. Biophys. Acta 893 (1987) 444-451.

24. R. Picorel, S. Lefebvre and G. Gingras. Oxido-reduction of B800-850 and B800 holochromes isolated from three species of photosynthetic bacteria as studied by electron paramagnetic resonance and optical spectroscopy. Eur. J. Biochem. 142 (1984) 305-311.

25. P.J.M. van Kan, S.C.M. Otte, F.A.M. Kleinherenbrink, M.C. Nieveen, T.J. Aartsma and H.J. van Gorkom. Biochim. Biophys. Acta 1020 (1990) 146-152.

26. H.-C. Chang, R. Jankowiak, N.R.S. Reddy, C.F. Yocum, R. Picorel, M. Seibert and G.J. Small. On the question of the chlorophyll a content of the photosystem II reaction center. J. Phys. Chem. 98 (1994) 7725-7735.

27. S.L.S. Kwa, C. Eijckelhoff, R. van Grondelle and J.P. Dekker. Site-selection spectroscopy of the reaction center complex of photosystem II. 1. Tripletminus-singlet absorption difference: search for a second exciton band of P680. J. Phys. Chem. 98 (1994) 7702-7711.

28. G. Montoya, R. Cases, R. Rodríguez, M. Aured and R. Picorel. Detergentinduced reversible denaturation of the photosystem II reaction center: Implications for pigment-protein interactions. Biochemistry 33 (1994) 1179811804. 
29. A.Ya. Shkuropatov, R.A. Khatypov, T.S. Volshchukova, V.A. Shkuropatova, T.G. Owens and V.A. Shuvalov. Spectral and photochemical properties of borohydride-treated D1-D2-cytochrome b559 complex of photosystem II. FEBS Lett. 420 (1997) 171-174.

30. L. Konermann and A.R. Holzwarth. Analysis of the absorption spectrum of photosystem II reaction centers: Temperature dependence, pigment assignment, and inhomogeneous broadening. Biochemistry 35 (1996) 829842.

31. D.A. Berthold, G.T. Babcock and C.F. Yocum. A highly resolved, oxygenevolving Photosystem II preparation from spinach thylakoid membranes. FEBS Lett. 134 (1981) 231-234.

32. E. Torrado, I. Yruela, M. Alfonso, M. Seibert and R. Picorel. Biochemical and spectroscopic analysis of a new D1-D2-Cytochrome b559 reaction center preparation isolated with high Triton X-100--Pigment stoichiometry and cytochrome content. Biochemistry (1999) submitted.

33. V.A. Shuvalov, U. Heber and U. Schreiber. Low temperature photochemistry and spectral properties of a photosystem II reaction center complex containing the proteins D1 and D2 and two hemes of Cyt b559. FEBS Lett 258 (1989) 27-31.

34. V.A. Shuvalov. Composition and function of cytochrome $b 559$ in reaction centers of photosystem II of green plants. J. Bioenerg. Biomem. 26 (1994) 619-626.

35. Braun, P. (1993) Ph.D. Thesis. The Weizmann Institute of Science, Rehovot.

36. B. Gall and H. Scheer. Stabilization of photosystem II reaction centers: influence of bile salt detergents and low pH. FEBS Lett. 431 (1998) 161-166. 
37. B. Svensson, C. Etchebest, P. Tuffery, P. van Kan, J. Smith and S. Styring. A model for the photosystem II reaction center core including the structure of the primary donor P680. Biochemistry 35 (1996) 14486-14502.

38. S.L.S. Kwa, N.T. Tilly, C. Eijckelhoff, R. van Grondelle and J.P. Dekker. Siteselection spectroscopy of the reaction center complex of photosystem II. II. Identification of the fluorescing species at 4K. J. Phys. Chem. 98 (1994) 77127716.

39. L. Konermann, I. Yruela and A.R. Holzwarth. Pigment assignment in the absorption spectrum of the photosystem II reaction center by site-selection fluorescence spectroscopy. Biochemistry 36 (1997) 7498-7502.

40. P. Braun, B.M. Greenberg and A. Scherz. D1-D2-Cytochrome b559 complex from the aquatic plant Spirodela oligorrhiza: correlation between complex integrity, spectroscopic properties, photochemical activity and pigment composition. Biochemistry 29 (1990) 10376-10387.

41. C. Eijckelhoff, F. Vacha, R. van Grondelle, J.P. Dekker and J. Barber. Spectroscopic characterization of a $5 \mathrm{Chl}$ a photosystem II reaction center complex. Biochim. Biophys. Acta 1318 (1997) 266-274.

42. M. Mimuro, T. Tomo, Y. Nishimura, I. Yamazaki and K. Satoh. Identification of a photochemically inactive pheophytin molecule in the spinach D1-D2-Cyt b559 complex. Biochim. Biophys. Acta 1232 (1995) 81-88. 


\section{FIGURE LEGENDS}

Figure 1.- Effect of the acid $\mathrm{pH}$ on the $\mathrm{Q}_{\mathrm{y}}$ band region of the absorption spectrum of the D1-D2-Cyt b559 complex. Control at pH 6.5 ( $\mathrm{a}$ and $\mathrm{b},-)$, treated at $\mathrm{pH} 5.5$ (a, ---) and $\mathrm{pH} 4.0(\mathrm{~b},---)$, and after washing the $\mathrm{pH}$-treated samples with buffer at $\mathrm{pH} 6.5$ ( $\mathrm{a}$ and $\mathrm{b}, \ldots .$.$) . Inset: \mathrm{Q}_{\mathrm{x}}$ absorption band region of the spectra. $\mathrm{c}$ ) Difference absorption spectra by subtracting the absorption spectra of D1-D2-Cyt b559 complex samples at pH 5.5 (1), pH 4.0 (3), and after washing the pH 5.5 (2) and 4.0 (4) treated samples with solution buffer at $\mathrm{pH} 6.5$, respectively, from that non-treated D1-D2-Cyt b-559 complex. Inset: Difference absorption spectrum between the $\mathrm{pH} 4.0$ treated sample after washing with buffer solution at $\mathrm{pH} 6.5$ and that at $\mathrm{pH}$ 4.0. Measurements were done at $77 \mathrm{~K}$ and to do that samples were diluted three times in glycerol. For details see Materials and Methods.

Figure 2.- Effect of the basic $\mathrm{pH}$ on the $\mathrm{Q}_{\mathrm{y}}$ band region of the absorption spectrum of the D1-D2-Cyt $b 559$ complex. Control at pH 6.5 ( $\mathrm{a}$ and $\mathrm{b},-)$, treated at $\mathrm{pH} 8.1$ (a, ---) and $\mathrm{pH} 10.0$ (b, ---), and after washing the pH-treated samples with buffer at $\mathrm{pH} 6.5$ ( $\mathrm{a}$ and $\mathrm{b}, \ldots . .$.$) . Inset: \mathrm{Q}_{\mathrm{x}}$ absorption band region of the spectra. $\mathrm{c}$ ) Difference absorption spectra by subtracting the absorption spectra of the D1-D2Cyt b559 complex samples at $\mathrm{pH} 8.1$ (1), $\mathrm{pH} 10.0$ (3), and after washing the $\mathrm{pH}$ 8.1 (2) and 10.0 (4) treated samples with solution buffer at $\mathrm{pH} 6.5$, respectively, from that non-treated D1-D2-Cyt $b$-559 complex. Inset: Difference absorption spectrum between the $\mathrm{pH} 10.0$ treated sample after washing with buffer solution at $\mathrm{pH} 6.5$ and that at $\mathrm{pH}$ 10.0. Measurements were done at 77K. Samples were diluted three times in glycerol. For details see Materials and Methods. 
Figure 3.- Second derivative absorption spectra of the $\mathrm{Q}_{y}$ band region of the D1D2-Cyt b559 complex in control conditions at pH 6.5 ( $\mathrm{a}$ and $\mathrm{b}, 1)$, and treated with buffer at pH $5.5(\mathrm{a}, 2), 4.0(\mathrm{a}, 4), 8.1(\mathrm{~b}, 2), 10.0(\mathrm{~b}, 4)$ and after washing the pH $5.5(a, 3), 4.0(a, 5), 8.1(b, 3)$ and $10.0(b, 5)$ treated samples with buffer solution at pH 6.5.

Figure 4.- Dependence of the $\mathrm{Q}_{y}$ absorption maximum of the D1-D2-Cyt $b 559$ complex on the subsequent freezing/thawing cycle treatment at $193 \mathrm{~K}(\bullet)$ and 77K (O). Samples were resuspended in $50 \mathrm{mM}$ Mes- $\mathrm{NaOH}(\mathrm{pH} 6.5)$ and $0.1 \%$ $n$-dodecyl- $\beta$ - $D$-maltoside. Absorption spectra were recorded at $4{ }^{\circ} \mathrm{C}$ after treatment.

Figure 5.- a) Absorption spectra in the $\mathrm{Q}_{y}$ band region of the D1-D2-Cyt b559 complex at $77 \mathrm{~K}$ after subsequent freezing/thawing cycle treatments at $193 \mathrm{~K}$. Inset: $\mathrm{Q}_{\mathrm{x}}$ absorption band region of the spectra. b) Difference absorption spectra between those of the treated and control samples. Number of freezing/thawing cycles $0(-), 4(---), 8$ (....). 

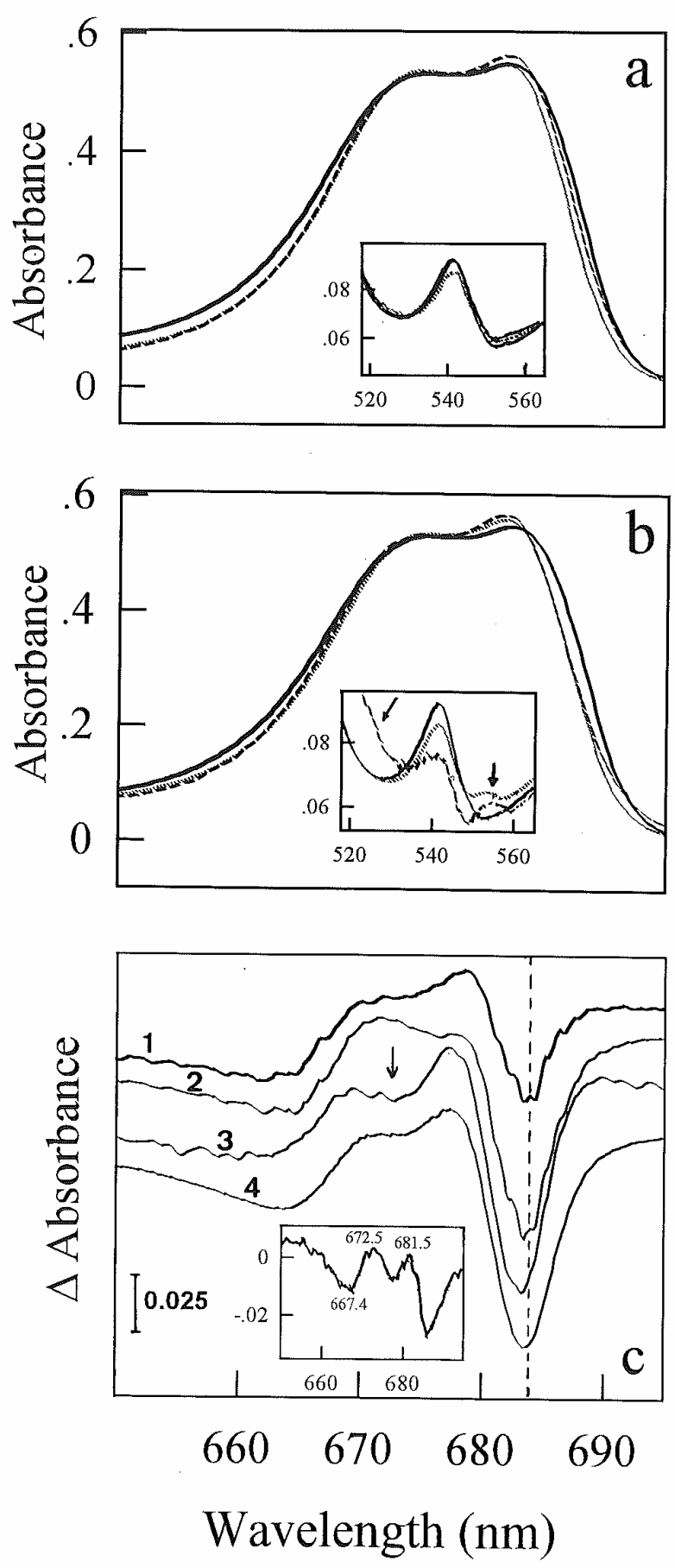

Fig.1 

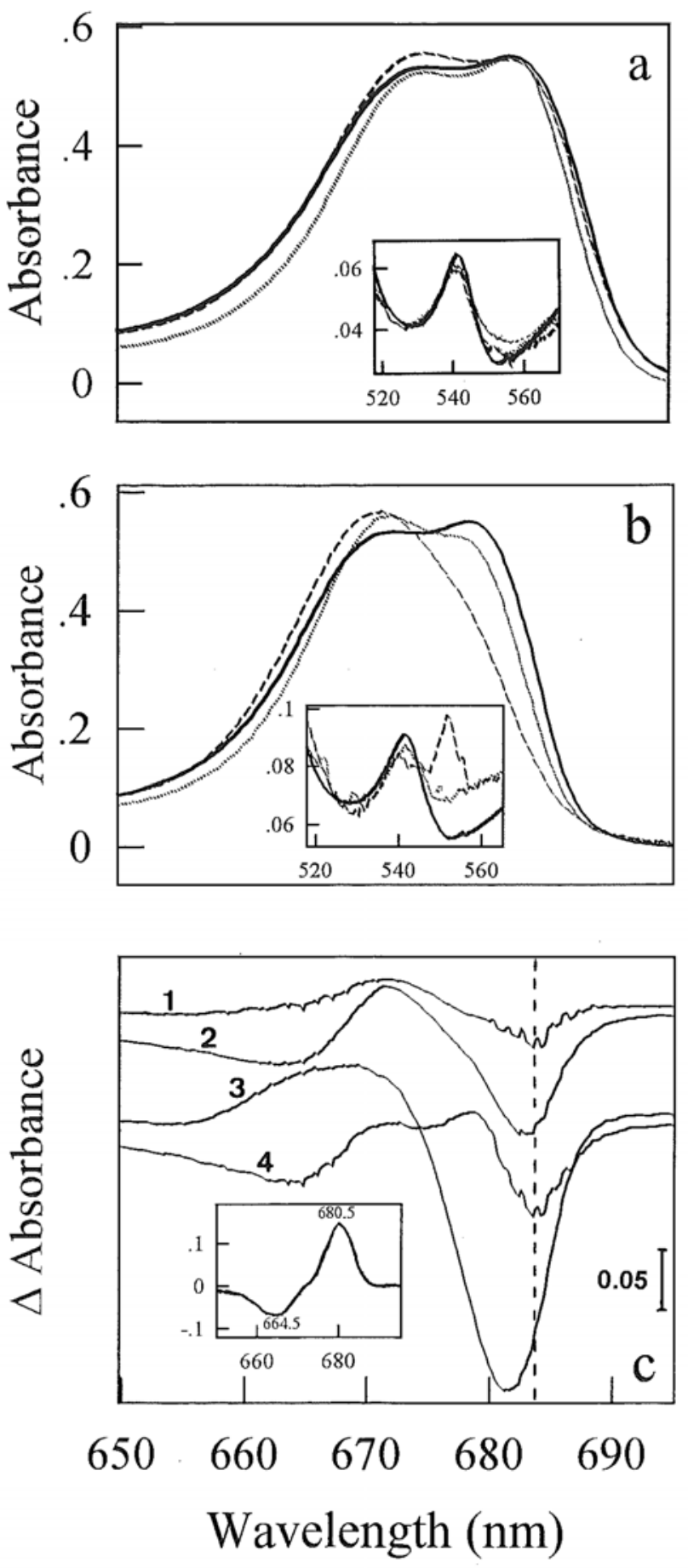

Fig. 2 

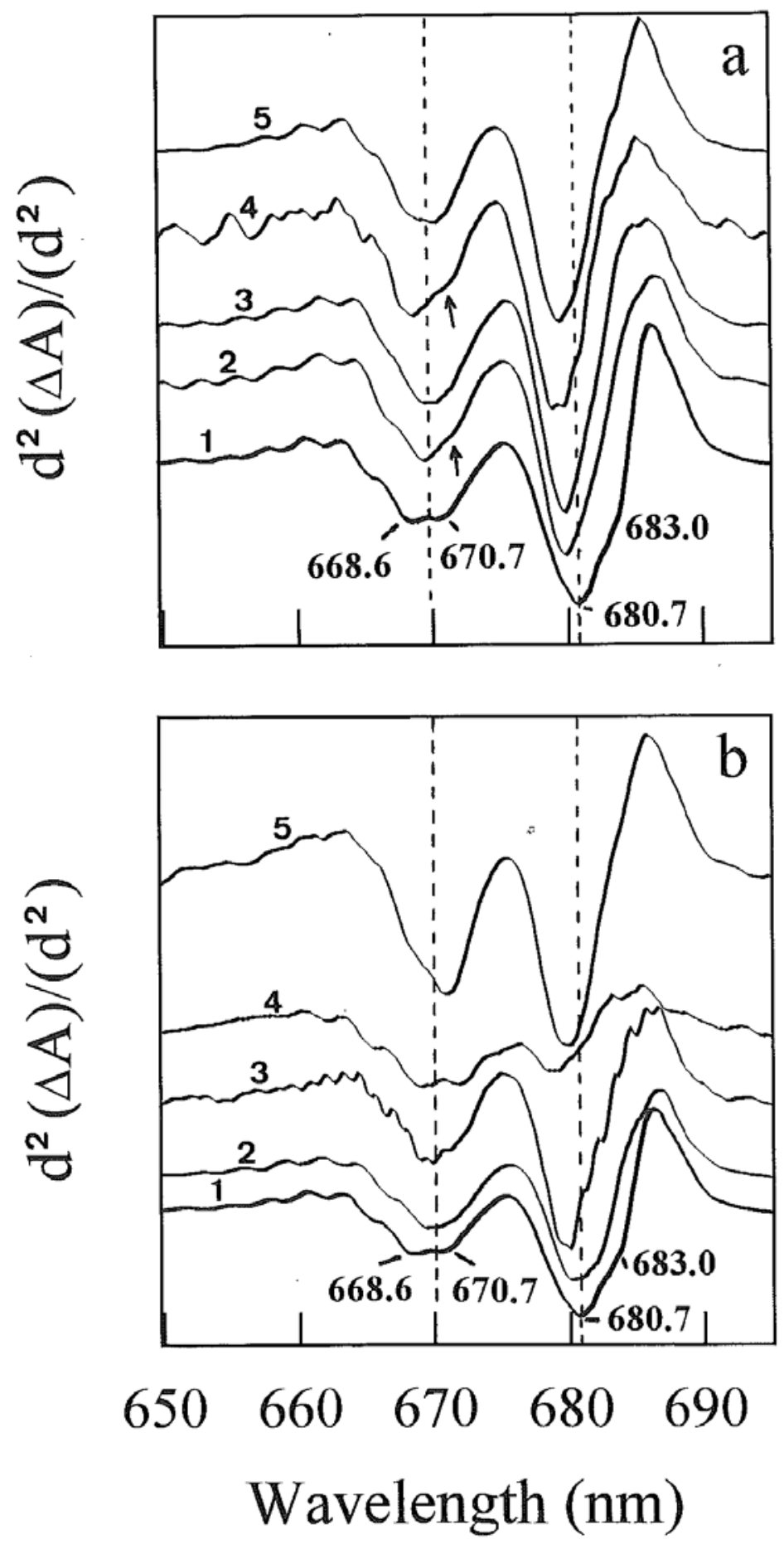

Fig. 3 


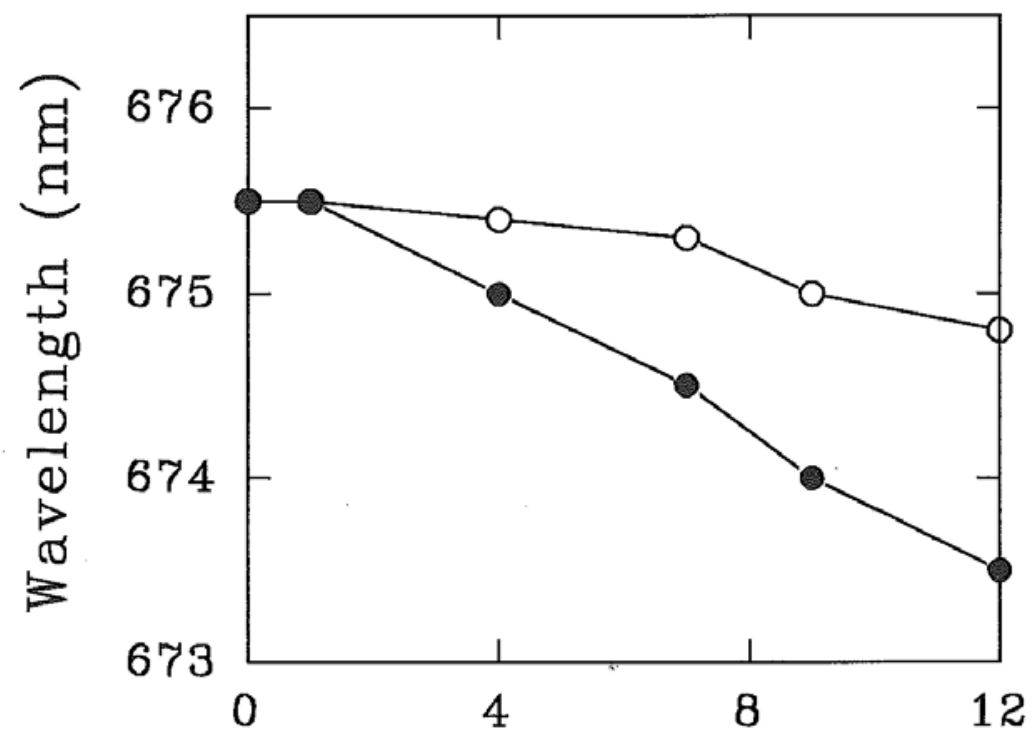

Freezing/Thawing cycles

Fig. 4 

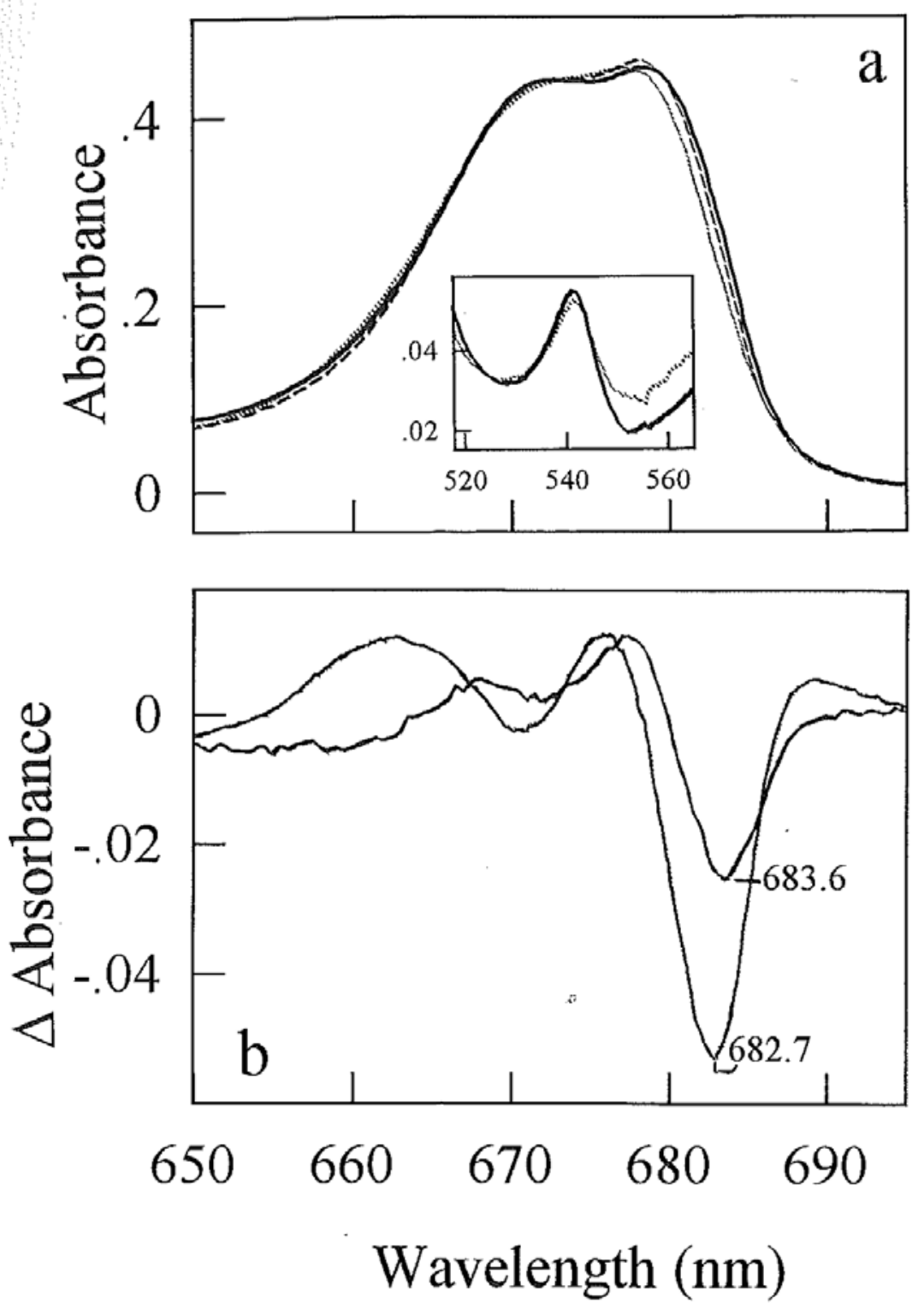

Fig. 5 